doi:10.12662/2359-618xregea.v10i1.p58-75.2021

ARTIGOS

\section{A TRAJETÓRIA EMPRESARIAL E OS MOTIVOS PARA ABERTURA E ENCERRAMENTO DE EMPRESAS}

\section{THE BUSINESS PATH AND THE REASONS FOR OPENING AND CLOSING COMPANIES}

\section{RESUMO}

O sucesso ou o fracasso das organizações podem impactar positiva e negativamente a economia de uma região, tendo em vista que os empreendedores enfrentam diversas dificuldades, cotidianamente, em seus empreendimentos e ao longo de suas trajetórias. Nesta perspectiva, este artigo objetiva discutir os motivos para abertura e encerramento de atividades empresariais, assim como as dificuldades enfrentadas ao longo de suas trajetórias. A presente pesquisa se define, então, como empírica, descritiva-exploratória e optou, como estratégia de pesquisa, pelo estudo de caso, com múltiplas unidades de análise. Adotaram-se, como instrumento de coleta, entrevistas semiestruturadas, com tratamento qualitativo dos dados coletados em campo. A amostra, definida pela técnica de snowball, possui nove empreendedores. Quanto aos resultados, verificou-se que as empresas enfrentam conflitos interpessoais e carecem de mão de obra especializada. Ademais, confirmou-se a importância do conhecimento para os empreendedores.

Palavras-chave: Dificuldades. Empreendedorismo. Motivos. Trajetória.

\begin{abstract}
The success or failure of organizations can positively and negatively impact the economy of a region, given that entrepreneurs face several difficulties, on a daily basis, in their ventures and throughout their trajectories. From this perspective, this article aims to discuss the reasons for opening and closing business activities, as well as difficulties faced along their trajectories. This research is defined, then, as empirical, descriptive-exploratory, and opted, as a research strategy, for the case study, with multiple units. of analysis. As a collection instrument, semi-structured interviews were adopted, with a qualitative treatment of the data collected in the field. The sample, defined by the snowball technique, includes
\end{abstract}


nine entrepreneurs. As for the results, it was verified that the companies face interpersonal conflicts and lack specialized labor. Furthermore, the importance of knowledge for entrepreneurs was confirmed.

Keywords: Difficulties. Entrepreneurship. Reasons. Trajectory.

\section{INTRODUÇÃO}

As organizações são instituições que possuem um grande impacto na sociedade em que estão inseridas, sejam bem-sucedidas ou não. O sucesso dos empreendimentos ou seus fracassos podem gerar empregos ou acabar com eles, modificando a economia de uma região positiva ou negativamente.

Estudos do SEBRAE (2016) mostram altos índices de mortalidade de empresas, indicando que, em até dois anos de sua existência, cerca de $24,4 \%$ das empresas brasileiras fecham as portas. De acordo com o mesmo estudo, esse percentual pode subir para até $50 \%$ em empresas que possuem menos de quatro anos de existência.

Os altos índices de mortalidade empresarial, portanto, indicam que as empresas brasileiras têm dificuldades em se manterem ativas, pelos mais diversos motivos, o que pode afetar a economia local como um todo. Há empresas, porém, que conseguem se manter e sobreviver, obtendo sucesso ao longo do caminho. Segundo o SEBRAE (2016), cerca de $76,6 \%$ das organizações sobrevivem até o segundo ano de sua existência, superando as dificuldades e os problemas que possam lhe afetar.

De acordo com Alves et al. (2010), os empreendedores são responsáveis por grande parte do desenvolvimento econômico; assim, é preciso compreender os aspectos referentes ao surgimento e a manutenção de seus empreendimentos, assim como os fatores que levam a seu encerramento, principalmente no que diz respeito às micro e pequenas empresas. Sendo assim, entende-se que conhecer, portanto, o perfil de empreendedores locais, que expe- rimentaram sucesso e fracasso e enfrentaram dificuldades, e levantar as causas que podem ter levado à tal situação, pode auxiliar outros empreendedores a compreender as dificuldades que envolvem ter um negócio próprio. $\mathrm{O}$ entendimento desses fatores pode, também, auxiliar na compreensão do mercado propriamente dito, assim como da competitividade que o caracteriza, das dificuldades, dos acertos e da trajetória dos empreendedores.

A literatura acerca dos motivos para a abertura e o encerramento de empresas e as dificuldades enfrentadas por esses empreendedores, em especial na região pesquisada, ainda é limitada; assim, a pesquisa busca ampliar o conhecimento e, por conseguinte, a literatura acerca do tema.

Dessa forma, o estudo objetiva levantar os motivos para abertura e encerramento de empreendimentos, bem como analisar as dificuldades e a trajetória de vida dos empreendedores pesquisados. Vale salientar que a presente pesquisa foi realizada entre 2018 a 2019, portanto, anterior ao contexto da pandemia do Covid-19, que gerou e ainda vem provocando inúmeros impactos sociais, políticos e econômicos na sociedade brasileira e mundial. $\mathrm{O}$ presente artigo está organizado em cinco partes, incluindo esta introdução. A segunda parte trata da revisão de literatura acerca de empreendedorismo, enquanto a terceira discute a questão da sobrevivência e mortalidade de empresas. A quarta parte apresenta os procedimentos metodológicos adotados. Por fim, a quinta analisa os dados empíricos à luz do referencial teórico e a última encerra com as considerações finais do estudo.

\section{EMPREENDEDORISMO}

O conceito de empreendedor vem sendo discutido e, por conseguinte, evoluindo com o passar do tempo, juntamente com a complexidade da economia mundial (MINELLO, 2010). Verin (1982 apud FILION, 1999), inclusive, considera que o uso do termo empreendedor, derivado do 
francês entrepreneur, obteve diversas conotações ao longo dos séculos. No século XII, tratava-se de alguém que incentivava brigas. No início do século XVII, era usado para alguém que tomava para si a responsabilidade militar. No fim deste e início do século XVIII, o termo passou a referir-se a um indivíduo que produzia ou criava projetos ou criava e conduzia empreendimentos. No entanto, para Gomes, Lima e Cappelle (2013), o termo empreendedorismo, ou empreendedor, no léxico português, são derivados de empreender, advindo da sua forma verbal latina imprehendo ou improehen$d o$, que significa a tentativa de execução de alguma tarefa, ou seja, a entrada desse termo no léxico português veio do latim, e não do francês entrepreneur.

Para Schumpeter (1985), empreendedorismo, por sua vez, é a capacidade de um empresário inovador combinar inovações tecnológicas e crédito. Desse modo, o empreendedor não precisa ser necessariamente o dono do capital, mas, sim, um agente com capacidade de mobilizá-lo, devendo ser alguém inovador (GOMES, 2010). Schumpeter (1985) conclui, então, que o empreendedor é um agente do processo de destruição criativa, sendo este o impulso fundamental para acionar e manter em marcha o motor econômico e, constantemente, criar novos produtos e novos mercados.

De acordo com Paulino e Rossi (2003), Jean Baptist Say descreveu a função do empreendedor como a de alguém responsável pela reunião de fatores de produção, condução administrativa e riscos associados à empresa. Trata-se, ainda de um indivíduo que possui iniciativa para criar um negócio, ou seja, alguém apaixonado pelo que faz e que utiliza os recursos disponíveis de uma forma criativa, a fim de transformar o ambiente social e econômico em que está inserido, aceitando os riscos e a possibilidade de fracassar. Dessa forma, é alguém que vê as oportunidades e percebe uma chance de capitalizar essa oportunidade, ao assumir os riscos e ganhos que podem ocorrer.

Smith (1986) define o empreendedor como um proprietário capitalista e Marshall (1985 apud PAULINO; ROSSI, 2003), por sua vez, como alguém que combina os fatores de produção, trabalho e capital, por meio de uma atividade energética, para gerar uma maior produção de bens e serviços, aumentando, assim, a riqueza total ou o bem-estar material de uma sociedade. Drucker (2011) afirma que os empreendedores são inovadores. Em outras palavras, a inovação é o instrumento específico dos empreendedores, ou seja, o meio que usam para explorar a mudança como oportunidade para um negócio diferenciado.

Shane e Venkataram (2000) corroboram o conceito de inovação proposto por Schumpeter, ao afirmarem que o empreendedorismo é um estudo das fontes de oportunidade, a fim de se criar algo novo. Trata-se, sobretudo, de um processo de descoberta, exploração e avaliação, por parte dos indivíduos, que usam diversos meios para atingir um fim (SHANE, VENKATARAMAN, 2000; VERGA; SILVA, 2014).

Para Verga e Silva (2014), a conceituação de empreendedor evoluiu ao longo dos anos e passou por três eras. A primeira, denominada econômica, ocorreu entre 1870 e 1940. A segunda, a era das ciências sociais, entre 1940 e 1970 . Dos anos 1970 até os dias atuais, ocorre a era dos estudos de gestão. Porém, para Filion (1999), o termo empreendedorismo passa por uma dicotomia, com uma vertente focada na economia e outra no comportamento. A primeira se relaciona com a visão de Schumpeter sobre 
inovação. A segunda segue ideias de McClelland (GEROLIM; ALBUQUERQUE; VERGA, 2010). Minello (2010) e Gomes (2010) afirmam que não há um consenso acerca dos conceitos de empreendedorismo e empreendedor.

Uma constante, desde a definição proposta por Schumpeter (1985), é a inovação, ou seja, a criação de algo novo, ou como pontuado por Marshall (1986) e Shane e Venkataram (2000): a combinação de fatores de produção a fim de gerar algo novo. Hirish e Peters (2004), por sua vez, definem o empreendedorismo como um processo de criar algo novo, com valor, em que se dedica o tempo e esforço necessários. Assume-se também riscos (que podem ser financeiros, psíquicos ou sociais) correspondentes e recebem-se recompensas. Tais recompensas podem ser satisfação pessoal e independência econômica.

No entanto, autores como Correa (2017) e Guimarães Júnior (2019) defendem que o empreendedor é aquele que apenas cria uma empresa. Santos, Barreto e Guzman (2017) compreendem o empreendedor de forma mais complexa, ao descrevê-lo como um indivíduo que promove mudanças no comportamento organizacional e no desenvolvimento econômico. Diante do exposto, é possível inferir que o empreendedor passou a ser visto como aquele que combina os fatores de produção, a fim de criar um negócio novo, assumindo os riscos e as recompensas atreladas à dedicação de seu tempo e esforço.

No entanto, a definição de Shane e Venkararaman (2000) é uma das mais aceitas, assim como a de Schumpeter, essencialmente econômica. Outra visão aceita é a comportamentalista, que enfatiza os traços de personalidade de empreendedores.

A noção de perfil empreendedor traz uma ideia que corrobora a visão comportamentalista, ao afirmar que existem certos traços de personalidade e características pessoais que tornam alguém empreendedor ou não e, por conseguinte, que podem tornar esse empreendedor um indivíduo de sucesso ou não. Filion (1991), ao abordar as características do perfil empreendedor, refere-se a esses indivíduos como sujeitos visionários, que veem de forma diferente, trabalham mais e com mais qualidade, estão sempre aprendendo, são líderes, têm conhecimento do setor em que estão e como sua atividade funciona, têm boas relações e possuem um bom networking. Para Julien (2010), existem condições para se manter um espírito empreendedor: manter o faro; conservar certa paixão; adquirir experiência; ter o apoio constante de pessoas próximas e do meio em que estão inseridos; conservar um espírito de liderança; renovar o senso de iniciativa e ter certa humildade diante da sorte.

Barros, Fiusa e Ipiranga (2005) referem-se a Bom Ângelo (2003) que identifica cinco elementos fundamentais para caracterizar o perfil empreendedor: (1) criatividade e inovação; (2) habilidade, que direcionam seus esforços criativos para objetivos determinantes e claros; (3) força de vontade e fé; (4) foco na geração de valor e; (5) capacidade de correr riscos. Drucker (2011), por sua vez, aponta quatro características que auxiliam a identificação do comportamento de um empreendedor: (1) busca da mudança; (2) capacidade de inovar; (3) senso de missão; (4) estabelecimento da cultura. Assim, segundo Greatti e Senhorini (2000), a persistência e a busca por informações se mostram como atributos importantes para a definição de empreendedor, constituindo-se, também, em aspectos que podem auxiliar a desenvolver os empreendimentos.

A noção de ação empreendedora pode auxiliar neste debate. Segundo Gomes (2010), tal noção abre uma possibilidade para se considerar que pessoas comuns podem, seja em grupo ou sozinhos, praticar uma ação empreendedora de caráter radical ou não. Assim, todos sem distinção podem ser empreendedores, sejam por ino- 
vações radicais ou incrementais, conforme defende Rogers (1995). De acordo com a teoria da ação empreendedora, o reconhecimento de uma oportunidade, aspecto comum em quase todas as definições de empreendedor, passa por dois pontos: a identificação e a avaliação das oportunidades. Segundo Mocelin e Azambuja (2017), a ação empreendedora pode ser definida como:

[...] a vontade concretizada de indivíduos que buscaram criar algo com potencial valorização social e em que previamente já depositavam expectativa de obter ganhos. Essa vontade depende da disposição dos agentes para desencadeá-la em uma linha regular de ação, que exige dispêndio de tempo e de recursos. Trata-se de um exercício reflexivo, no qual os agentes pressupõem possíveis consequências de suas ações, embora não as possam controlar inteiramente no curso da ação. Ao tomar decisões, o agente empreendedor passa a agir sobre suas escolhas - o caminho que julgou mais adequado seguir - e a monitorar determinada linha de ação que desencadeou (MOCELIN; AZAMBUJA, 2017, p. 14).

Desse modo, a ação empreendedora envolve práticas decisórias com uma maior profundidade subjetiva. Tais práticas decisórias estão vinculadas à iniciativa de alguns indivíduos de agir sobre uma oportunidade que, para eles, vale a pena seguir (MCMULLEN; SHEPHERD, 2006; HAYNIE et al., 2009 apud MOCELIN; AZAMBUJA, 2017). Ainda segundo essa noção, a racionalidade dos empreendedores é limitada às informações que eles possuem e à sua capacidade cognitiva para acessar e processar novas informações na forma de empreendimentos (MOCELIN; AZAMBUJA, 2017). Em meados do século passado, embora da vertente econômica, Schumpeter (1985) já associava a ação empreendedora a traços de personalidade do empreendedor, como a criatividade, realização pessoal, energia, o poder, no que se refere à capacidade de fazer, e superioridade. Segundo Lenzi e Santiago (2010, p. 14), "os empreendedores com ação empreendedora agem de forma consciente e sistematizada na realização de seus objetivos de curto, médio e longo prazo."

Ademais, a ação empreendedora deve estar presente em todas as atividades do empreendedor, sejam elas pessoais ou profissionais, visto que as competências se desenvolvem ao longo de uma evolução gradativa. Assim, a ideia de ação empreendedora auxilia no entendimento de que as ditas características que um indivíduo deve possuir para se tornar um empreendedor são constructos. Como afirma Boutilier (2003 apud JULIEN, 2010), não se nasce um empreendedor. No entanto, aprende-se a ser um.

Desse modo, afirmar que um sujeito, para ser considerado empreendedor, deve apresentar tais características, é criar um estereótipo em torno da definição e do perfil que supostamente forma um empreendedor. De acordo com Gomes (2010), estereótipos são modelos rígidos em que o comportamento social de um ator é interpretado, sem considerar a sua intencionalidade, subjetividade e contexto. Assim, cria-se um consenso social em torno dessas características, o que exclui quem não se enquadra nesse modelo e deixa o termo empreendedor e a possibilidade do sucesso restritos somente aos atores que apresentam tais características. Em outras palavras, os indivíduos que não apresentam tais atributos não seriam empreendedores e, se fossem, seriam fadados ao fracasso, o que pode não se sustentar na realidade.

\section{SOBREVIVÊNCIA E MORTALI- DADE DE EMPRESAS}

A mortalidade de uma empresa refere-se à sua falência (COUTO; CAMPOS; CASTRO, 2016), enquanto a sobrevivência, à sua continuidade. Assim, a presença de uma organização no mercado é o parâmetro para a realização de pesquisas desenvolvidas pelo SEBRAE. Segundo dados do SEBRAE (2016), a taxa de sobrevivência das empresas, com até dois anos de funcionamento, conforme a figura 1 , foi de $54,2 \%$, em 2006, e 55,4\%, em 2009. Desde 2010, subiu consideravelmente para $76,2 \%$, 
não obstante uma queda em 2011 e uma retomada de crescimento da taxa em 2012.

Figura 1 - Taxa de Sobrevivência de Empresas de dois anos: evolução no Brasil

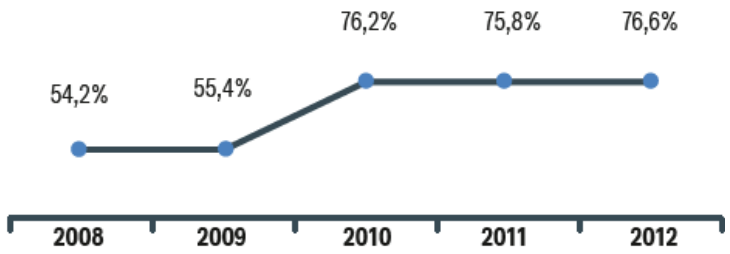

Fonte: (SEBRAE, 2016, p. 16).

Existem diversos fatores que podem influenciar a sobrevivência das empresas, sejam externos ou internos à organização. Entre os fatores externos, estão a implantação de medidas, como o Simples Nacional, que se referem à implantação dos regimes fiscais diferenciados para as micro e pequenas empresas (em âmbito estadual e municipal), assim como programas de recuperação fiscal e capacitação dos empreendedores (SEBRAE, 2008). Os fatores internos envolvem o planejamento gerencial e o comportamento empreendedor, propriamente dito (SEBRAE, 2010).

Segundo Borges e Oliveira (2014), alguns dos fatores que proporcionam uma maior taxa de sobrevivência para as empresas são o aquecimento da economia, os avanços da legislação, o aumento da escolaridade dos empreendedores e um forte crescimento do mercado consumidor interno. Isso indica que a junção de fatores externos e internos seria mais eficaz para a sobrevivência das empresas.

Valcácio et al. (2017) afirmam, também, que alguns dos fatores importantes para o sucesso e a sobrevivência de empresas são: a pesquisa do mercado externo e fortes orientações empresariais; o planejamento e a tomada de decisão e inovação; o comportamento proativo e de caráter inovador; a escolha do negócio a ser empreendido. Ademais, os autores incluem outros fatores, tais como: a definição de políticas e estratégias de compra e venda; a qualidade de contabilidade financeira/gerencial; a formulação de estratégias; as práticas gerenciais e de empreen- dedorismo; as práticas gerenciais (antecipação de acontecimentos e a procura por informações relevantes); a relevância à informação contábil para a tomada de decisão; as medidas para diminuição da inadimplência; o planejamento tributário; o aumento do capital de giro; a consultoria especializada em gestão pelo contador; os maiores investimentos de recursos financeiros na empresa; a aderência ao simples nacional; o capital social (existência de pessoas na família com negócios similares), etc.

Os estudos do SEBRAE (2008) afirmam que os fatores que contribuíram para a diminuição da porcentagem de mortalidade das empresas e sua consequente sobrevivência são: melhoria no ambiente dos negócios, ou seja, no meio em que a empresa está inserida; qualificação dos empresários; mudança no perfil das empresas, ao buscarem atender mais às necessidades dos clientes e preparem-se para tal; e planejamento prévio. A melhora no planejamento prévio não se aplica à gestão empresarial em si, quando a empresa já está aberta. No que tange ao perfil dos empresários, o SEBRAE (2008) afirma que houve um aumento do grau de escolaridade dos empreendedores, o que pode lhes garantir um maior conhecimento sobre a área em que pretendem atuar. Isso, inclusive, pode explicar o aumento do número de empreendedores por oportunidade que, segundo Couto, Campos e Castro (2016), chegou a cerca de $70,6 \%$.

Segundo os próprios empreendedores pesquisados pelo SEBRAE (2010), os fatores que mais afetaram a sobrevivência de seus empreendimentos foram o planejamento antes da abertura da empresa, a adequada gestão após a sua abertura, o estabelecimento de políticas governamentais de apoio aos pequenos negócios, a estabilização da economia brasileira e a separação do pessoal e do profissional, evitando que problemas pessoais afetem os negócios. A relação do empreendedor com as pessoas ao seu redor também pode afetar a sobrevivência e a visão do empreendedor do seu próprio negócio. Seja com membros de sua família, ou outrem, as relações estabelecidas pelos empreendedo- 
res têm-se tornado um fator levado em consideração para a condução do empreendimento (FILION, 1993).

Existem diversos motivos pelos quais uma empresa pode ser aberta. Machado et al. (2003, p. 2) afirmam que, entre as mulheres, a razão mais predominante para a criação das empresas foi a "realização pessoal, seguida da visão de oportunidade de mercado e insatisfação no emprego. Predominou um tempo prévio de experiência profissional de nove anos, em média, e a existência de pais como modelos de empreendedores para $41 \%$ dos casos." Dessa forma, a realização pessoal e a experiência prévia se mostram predominantes na escolha por abrir um negócio próprio. É preciso entender, no entanto, que não é somente um fator que afeta a sobrevivência ou a mortalidade de uma empresa, ou seja, é um conjunto de ações e fatores combinados que levam uma empresa a sobreviver e se manter aberta (SEBRAE, 2008).

De acordo com estudos do SEBRAE, "o custo da mortalidade de empresas para sociedade é expressivo sob o ponto de vista de eliminação de postos de trabalho e da perda financeira." (SEBRAE, 2008, p. 67). Dessa forma, o encerramento das atividades de uma empresa, dependendo do seu tamanho, pode causar problemas para toda a sociedade em que está inserida, visto que a economia local por inteiro pode ser afetada. Sendo assim, existem ainda diversos fatores que podem levar ao encerramento de uma empresa. Desse modo, é impossível atribuir somente a um fator a causa da mortalidade de uma organização (SEBRAE, 2008). Em suma, há diversos motivos pelos quais uma empresa pode encerrar suas atividades. Segundo o SEBRAE-SP (2010), cerca de $18 \%$ das empesas fecham por falta de clientes, $10 \%$ por falta de capital, $10 \%$ por problemas de planejamento, $9 \%$ por perda do cliente único, $8 \%$ por problemas com sócios, $8 \%$ porque encontrou outra atividade, $7 \%$ fecharam por custos elevados, assim como $7 \%$ por problemas particulares, $7 \%$ por falta de lucro e $15 \%$ por outros motivos.

Ainda segundo o SEBRAE (2008), existem seis grandes conjuntos de fatores que podem contribuir para o encerramento prematuro de um negócio: (1) ausência de um comportamento empreendedor; (2) ausência de planejamento adequado; (3) deficiência no processo de gestão empresarial; (4) insuficiência de políticas públicas de apoio à gestão de pequenos negócios; (5) dificuldades oriundas da conjuntura econômica e; (6) impacto de problemas pessoais sobre os negócios.

Filardi (2006), por sua vez, organiza os motivos para a mortalidade das empresas em três grandes blocos: o empreendedor, os negócios e o ambiente externo. Tal organização é similar à divisão proposta pelo SEBRAE. O campo do empreendedor se refere à competência na gestão empresarial, à experiência no ramo, ao nível de escolaridade e à profissionalização da relação com os sócios. O campo dos negócios se refere ao acesso ao crédito, à mão de obra qualificada, ao planejamento estratégico, ao suporte jurídico e contábil e à qualidade produtos/serviços e inovação produtos/serviços. $\mathrm{O}$ último bloco, sobre o ambiente externo, refere-se à burocracia legal e fiscal, à competição dos concorrentes, à demanda dos clientes, aos fornecedores, representantes, aos distribuidores e parceiros, à carga de impostos e tributos e aos aspectos econômicos, políticos, tecnológicos, sociais e ambientais. Desse modo, entende-se que existem diversas causas para a mortalidade das empresas brasileiras. Geralmente, é a relação de dois ou mais fatores que pode contribuir para que as empresas entrem em falência.

\section{PROCEDIMENTOS METODOLÓ- GICOS}

O presente artigo se classifica, quanto à sua natureza, em uma pesquisa empírica, pois se caracteriza pela experimentação da realidade, utilizando técnicas de coleta, mensuração e manipulação de dados e fatos, que permitem a descoberta da realidade (DEMO, 1982). Com isso, pretende-se analisar os dados coletados a fim de se conhecer melhor a realidade na qual estão inseridos. Quanto aos seus objetivos, classifica-se como descritivo-exploratória, visto que se busca pro- 
porcionar uma maior familiaridade com o problema, visando torná-lo mais explícito, assim como descrever as características de uma determinada população ou fenômeno e estabelecer relações entre variáveis (GIL, 2002).

Acerca de seus procedimentos, optou-se pelo estudo de caso, com múltiplas unidades de análise, visto que tal técnica permite o conhecimento detalhado e amplo sobre um ou poucos objetos (GIL, 2008; YIN, 2001). Visto que há um alto grau de complexidade em conhecer a população da pesquisa, optou-se por uma amostragem não probabilística, utilizando a técnica de snowball, de acordo com o critério de conveniência. A técnica de snowball utiliza-se de redes de referência ou indicações. Desse modo, torna-se útil quando se deseja pesquisar grupos difíceis de serem estudados ou acessados ou, até mesmo, quando não se conhece o universo de pesquisa ou, até mesmo, quando se pretende estudar questões delicadas ou de âmbito privado (VINUTO, 2014). Ademais, intencionalmente, buscou-se investigar casos de sucesso e de fracasso empresarial na cidade de Vitória da Conquista, Região Sudoeste da Bahia.

Utilizando-se, então, a técnica de snowball, chegou-se a seis intermediários e uma amostra de 41 empreendedores. Desse total, nove aceitaram ser entrevistados, quatro pediram mais tempo para definir sua participação; no entanto, não houve tempo hábil para a sua entrevista, e 28 se recusaram a participar. Sendo assim, a amostra da pesquisa compreendeu um total de nove empreendedores que atuam ou atuaram como empresários na cidade de Vitória da Conquista. Para preservar a identidade dos informantes, eles foram nomeados com nomes com a pronúncia em português de letras do alfabeto grego.

$\mathrm{O}$ instrumento de coleta dos dados foi a entrevista semiestruturada, visto que permite a elaboração de novas perguntas ao longo da entrevista (GIL, 2008) e possibilita conhecer e entender melhor as percepções dos sujeitos acerca do sucesso e fracasso enfrentado.
Tendo em vista os objetivos da pesquisa, os dados receberam tratamento qualitativo. Segundo Dyniewicz (2009), tal abordagem baseia-se na premissa de que o conhecimento sobre as pessoas só é possível pela descrição das experiências humanas, tais como são vividas e definidas pelos próprios atores.

Em suma, após definidos os procedimentos metodológicos que seriam adotados para coleta dos dados empíricos bem como a elaboração dos instrumentos de coleta de dados, realizaram-se os primeiros contatos com os empreendedores. Embora muitos tenham rejeitado participar da pesquisa, deu-se o início das primeiras entrevistas que, por sua vez, levaram a outras em função da técnica do snowball. Ao fim da coleta de dados, os dados foram analisados à luz do referencial teóricos.

\section{TRAJETÓRIA EMPRESARIAL}

Os empreendedores foram questionados acerca de características gerais de seu perfil, assim como do tipo de negócio e idade de seus empreendimentos. Dessa forma, o perfil dos entrevistados é de uma maioria de homens, entre 31 e 50 anos de idade, casados, com dois filhos, que estudaram até o ensino superior incompleto, não participaram de cursos além da sua formação escolar e atuam no negócio há nove ou mais anos. Seus empreendimentos são, em sua maioria, comerciais ou do ramo de serviços e existem há, pelo menos, 10 anos. Ademais, parte dos empreendedores pesquisados possui ou possuiu mais de uma empresa ao longo de sua trajetória empresarial.

Quanto à trajetória, os entrevistados foram questionados acerca da área de atuação anterior ao estabelecimento do próprio negócio, das influências para montar o próprio negócio, dos erros e acertos, além de sua trajetória de vida empresarial propriamente dita. Ao serem questionados acerca do trabalho anterior, os empreendedores pesquisados indicaram uma trajetória de trabalho árduo, 
como ambulantes e em empresas familiares, condizendo com a realidade local, em que a maior parte das empresas advém de empreendimentos familiares. Outros empreendedores pesquisados indicaram que trabalharam em empreendimentos similares aos que abriram. Os empreendedores Alfa e Beta confirmam essas dificuldades ao comentarem que "Trabalhava pra mim mesmo, comerciante ambulante" (Empreendedor Alfa) e "[...] trabalhei no mesmo ramo de baterias e aprendi que meu pai era do ramo já de baterias, e eu aprendi a parte elétrica junto de um funcionário que trabalhou na loja com ele" (Empreendedor Beta).

Os motivos para abertura do empreendimento envolvem, na maior parte dos casos, a existência previa de experiência no ramo, tal como a que o Empreendedor Beta cita acima. O Empreendedor Diagrama relata que abriu sua empresa, pois já trabalhava no ramo há muito tempo e compreendeu que possuía uma oportunidade de trabalhar por conta própria. Outros motivos envolvem o empreendedorismo por necessidade e a influência de membros familiares ou outras pessoas, como indica o empreendedor Beta:

No caso assim, quando é eu trabalhei com meu pai, a gente sempre, desde pequeno quis ter o próprio negócio né e aí foi passando os tempos e aí a gente foi, eu comecei a trabalhar muito novo, com 12 anos de idade e com 21 anos eu abri meu primeiro negócio, e depois, foi uma oficina e depois e saí da sociedade e abri meu próprio negócio (Empreendedor Beta).

A pesquisa de Machado et al. (2003), assim como a presente investigação, concluiu que os principais motivos para abertura de empresas são a realização pessoal, a visão de uma oportunidade de negócio e a insatisfação com o emprego anterior. Os achados de Machado et al. (2003) a respeito do papel desempenhado pela experiência prévia e pela influência do modelo de pais empreendedores para a abertura de empreendimentos também foi verificada nesta pesquisa. O Empreendedor Gama, sucessor de uma empresa familiar, afirmou que o processo de sucessão da empresa foi algo natural para ele, visto que acabou envolvendo-se muito com o empreendimento.

O depoimento do Empreendedor Eta, "Eu sou bastante inquieto, eu gosto de criar coisas, coisas que impactam na vida das pessoas então eu gosto realmente de fazer isso", remete às proposições de Hirish e Peters (2004), ao afirmarem que o empreendedorismo é o processo de criação de algo novo, em que se dedicam os esforços necessários e se assumem os riscos correspondentes à atividade realizada. E, como apontam Farah et al. (2008), os empreendedores são capazes de inovar e criar, aproveitando diversas oportunidades que acabam por mudar a sociedade em que estão inseridos. Dessa forma, para esse empreendedor, a criação de algo novo e a vontade de impactar as pessoas são o que lhe remete ao ser empreendedor.

Zeta compreende que o empreendedor vê que o empreendedorismo é visto como algo inerte ao indivíduo, que vem de dentro: "Não somente assim a oportunidade de ter um negócio próprio e a questão empreendedora, assim que a gente já tem no sangue e segui nesse sentido". No entanto, a noção de ação empreendedora compreende que todos podem ser empreendedores, envolvendo práticas decisórias com maior profundidade subjetiva (MOCELIN; AZAMBUJA, 2017). A ideia de que o empreendedorismo é somente para indivíduos que já nasceram com determinadas características é resultado de um constructo, ou seja, de um estereótipo criado em torno do termo e do perfil esperado pelo sujeito empreendedor. Muitos empreendedores pensam e disseminam essa ideia. No entanto, a literatura aponta que tais características são construídas ao longo da trajetória empresarial dos indivíduos e de suas experiências (GOMES, 2010). 
Quanto ao fator que influenciou a abertura das empresas, os empreendedores indicam desde a vontade de crescer e ter o próprio negócio até as influências familiares ou societárias, além de referências a outros empresários de sucesso que atraíram a admiração daqueles que pensam em se tornar empreendedores, conforme afirma o Empreendedor Eta: "São referências que eu tenho, como Steve Jobs, eu acho que é uma grande influência pra mim. As referências de pessoas que eu admiro". Para Filion (1993), as relações familiares ou não podem influenciar ou, até mesmo, moldar a visão do empreendedor sobre o seu negócio, à medida que as relações internas passam a ser mais importantes do que as externas, em se tratando da condução de seus empreendimentos.

Sobre o motivo mais importante para os empreendedores montarem seus negócios, a vontade de possuir coisas é apontada pelo Empreendedor Alfa, que se tornou empreendedor por necessidade. O exemplo familiar, a possibilidade de obter lucro e a existência prévia de conhecimento técnico sobre a área da qual iria se inserir são indicados pelos empreendedores Alfa, Epsilon e Diagrama. "Não, você sabe a pessoa ela sempre tem vontade de ter. Você sabe, vontade de ter uma bicicleta, de ter um sapato, tem vontade de ter um carro, de ter uma casa própria, tem tem desejos, quem não tem geralmente pensa naquilo alí, né?." (Empreendedor Alfa).

Para o Empreendedor Epsilon, o exemplo familiar, em especial, a trajetória de vida de seu pai, a luta de seu pai, que começou a trabalhar desde muito jovem foi o que mais impactou na sua própria jornada. Esse exemplo familiar, que é intensificado por meio das relações pessoais, é considerado por Machado et al. (2003) e Filion (1993) como sendo de extrema importância para os empreendedores, seja na abertura do negócio, seja na sua manutenção. Porém, o Empreendedor Diagrama afirmou que a possibilidade de ter lucro foi o fator mais importante, visto que já possuía experiência no ramo e acreditava na possibilidade de lucro.

O Empreendedor Beta afirmou que a inspiração e o conhecimento inicial para a criação de seu empreendimento vieram justamente de sua infância, trabalhando no empreendimento do pai, conforme pode ser observado no trecho selecionado abaixo.

Foi que era empresa pequena, empresa familiar e eu era o filho homem da casa e aos 12 anos já comecei, fazer mandata, ir no banco, trocar dinheiro, ficar ali no balcão enquanto ele ia fazer alguma coisa só que na época ele mexia só com bateira e depois surgiu a necessidade dele colocar um eletricista, que o pessoal sempre pedia e foi quando esse eletricista entrou que eu me interessei pela área, ficava ajudando a trocar lâmpada e e fazendo uma coisinha e outra (Empreendedor Beta).

Para o Empreendedor Zeta, o fato de ter começado a trabalhar cedo lhe mostrou a necessidade de se obter uma formação e se adequar aos mercados aos quais pretendia se inserir. Preparo e conhecimento, portanto, deram base para a criação do seu próprio negócio, corroborando o proposto por Machado et al. (2003), ao abordarem a influência da experiência prévia na abertura de empreendimentos.

Outro aspecto abordado por um dos empreendedores (Empreendedor Eta), como ponto importante para abertura do negócio, foi a construção do seu futuro e da sua família, além da realização do desejo da criação do próprio negócio.

O Quadro 1 sumariza os motivos para abertura e encerramento dos empreendimentos por parte dos empreendedores entrevistados. 
Quadro 1 - Motivos para abertura e encerramento

\begin{tabular}{|l|l|l|}
\hline EMPREENDEDOR & \multicolumn{1}{|c|}{ ABERTURA } & \multicolumn{1}{|c|}{ ENCERRAMENTO } \\
\hline Alfa & Necessidade & \\
\hline Beta & $\begin{array}{l}\text { Conhecimento advindo de Trabalho anterior } \\
\text { Empresa familiar }\end{array}$ & $\begin{array}{l}\text { Problemas na sociedade } \\
\text { Falta de conhecimento do ramo }\end{array}$ \\
\hline Gama & $\begin{array}{l}\text { Conhecimento advindo de trabalho anterior } \\
\text { Empresa familiar }\end{array}$ & \\
\hline Delta & Conhecimento advindo de trabalho anterior & \\
\hline Epsilon & Influência familiar & Problemas financeiros \\
\hline Diagama & Conhecimento advindo de trabalho anterior & $\begin{array}{l}\text { Problemas financeiros } \\
\text { Busca de crescimento profissional }\end{array}$ \\
\hline Zeta & Oportunidade de Empreendedorismo & Problemas financeiros \\
\hline Eta & Vontade de criação & \\
\hline Teta & Empresa familiar & \\
\hline
\end{tabular}

Fonte: elaboração própria (2021).

O Empreendedor Zeta afirmou que o conhecimento foi muito importante para o crescimento de seu empreendimento, visto que pode aprender o sentido técnico do que ocorria dentro da empresa, e guiá-la da melhor forma. Filion (1991) corrobora ao afirmar que os empreendedores estão sempre aprendendo e buscando conhecimento do setor em que estão inseridos. A busca por capacitação também é citada por Borges e Oliveira (2014) como um dos fatores que proporciona maiores taxas de sobrevivência para as empresas. Se por um lado o Empreendedor Zeta referiu-se à importância do conhecimento, por outro, o Empreendedor Beta tratou da falta de conhecimento como um dos fatores que o levou a encerrar suas atividades, visto que não conhecia muito o ramo do qual havia se inserido. Para o SEBRAE (2014), a falta de conhecimento técnico da área pode levar ao fracasso do empreendimento. De acordo com Drucker (2011), o empreendedor enxerga o conhecimento como uma forma para chegar ao desempenho organizacional. Para Nassif, Ghobril e Amaral (2011), o conhecimento por si só não é uma forma de se conseguir sucesso, apesar de ser considerado um facilitador, pois o conhecimento é mais do que as informações sobre como as coisas acontecem. Em outras palavras, ele inclui técnicas e informações que o empreendedor deve compreender a fim de manter o desempenho adequado e satisfatório de seu empreendimento.

Outros fatores que levaram ao encerramento das atividades foram fatores financeiros, como a perda de cliente único (Empreendedor Diagrama): "[...] e fechei por que, assim quando eu comecei, tinha experiência na parte do trabalho, mas não tinha experiência na parte de vendas de trabalho de lidar com os clientes e foi o motivo que tive que parar e fechar". A perda de clientes é indicada pelo SEBRAE (2008) como um dos motivos pelos quais muitos empreendedores encerram suas atividades. A necessidade de buscar outras formas de sustento, além da própria empresa, levou o Empreendedor Zeta ao afastamento do negócio, e a antecipação de prejuízos futuros forçou o empreendedor Eta a encontrar outros negócios ou novas formas de fazer o mesmo negócio.

Quanto aos fatos mais importantes nas carreiras profissionais, os empreendedores indicaram a "honestidade e trabalho" (Empreendedor Alfa), a capacidade de inovação, o fato de não se acomodar e buscar continuamente pelo "novo" (Empreendedor Beta) e a constante capacitação. 
Essa visão acadêmica depois que eu entrei na faculdade eu uma, você pensava de uma forma e depois mudou quase que totalmente, estava num mundo que poderia não ser no futuro satisfatório e com essa mudança e visão acadêmica abriu vários horizontes e não parou essa, procurando mai. (Empreendedor Gama).

Para o Empreendedor Gama, a formação superior e a capacitação mudaram a sua visão de mundo, abrindo horizontes. Tais formações devem ser constantemente perseguidas, tendo em vista que o crescimento da escolaridade dos empreendedores é um fator importante para o sucesso de um empreendimento (BORGES; OLIVEIRA, 2014). O Empreendedor Diagrama relata que o aprendizado também foi muito importante em sua trajetória empresarial, porém, aprendeu e desenvolveu suas habilidades no exercício da profissão e não por meio do ensino tradicional.

Tipo assim, é, no caso essa questão que impactou deu ter aprendido muitas coisas, que pouca gente, de eu ter aprendido na área profissional que poucas pessoas fazem e isso foi uma das coisas que me impactou, eu ter pegado bastante experiência (Empreendedor Diagrama).

O empreendedor Eta também considera que a busca por conhecimento foi o seu maior acerto. No entanto, retrata que o fato mais importante em sua trajetória foi a criação de uma de suas empresas. Tal criação representou um divisor de águas, demarcando sua vida antes e depois da implantação da empresa: "Eu coloco o [Empresa Eta] como um divisor de águas, antes do [Empresa $E t a]$ eu era um cara que tentava fazer as coisas sem tanto conhecimento e depois do [Empresa $E t a]$ eu mergulhei em conhecimento".

Os empreendedores Zeta e Beta também afirmam que sua busca por conhecimento foi um grande acerto. Para o Empreendedor Beta, o seu conhecimento técnico foi um de seus acertos, visto que conseguiu transformar seu negócio em realidade lucrativa, ao invés de uma "utopia", ao unir a visão empreendedora e a visão empresarial.

Dessa forma, o Empreendedor Beta atua tanto de forma gerencial como de forma empreendedora. Gomes (2010) afirma que estas são ações distintas, porém, complementares entre si, sendo necessárias e podendo ser desempenhadas por um indivíduo ou um grupo de indivíduos inseridos em um dado contexto. $\mathrm{Ou}$ seja, para o bom funcionamento e desenvolvimento dos negócios, é vital que se unam tais concepções, tratando-as como complementares e não divergentes.

Quanto aos erros, decepções, dificuldades e problemas enfrentados pelos empreendedores, destacam-se os conflitos interpessoais, sobretudo com funcionários (Empreendedor Alfa), falta de mão de obra especializada e sobrecarga de atividades, por falta de capacidade de delegação, e o crescente número de concorrentes (Empreendedor Beta). O Empreendedor Gama referiu-se a problemas com fornecedores, assim como os empreendedores Delta, Epsilon e Teta. As dificuldades com fornecedores, a falta de clientes e a inexperiência no ramo são fatores citados pelo SEBRAE $(2010,2014)$ e Filardi (2006) como fatores que podem levar à mortalidade das empresas.

A Empreendedora Teta considera que o processo de compra e venda de mercadorias é instável, pois: "[...] você tanto ganha como perde, depende da tua compra, que, às vezes, você compra um farelo de trigo, duas carretas, e o preço cai e você tem que se manter". Em outras palavras, o empresário deve analisar cuidadosamente todos os elementos que influenciam seu empreendimento, inclusive, considerar o impacto de suas decisões, sejam boas ou ruins, em longo prazo.

No entanto, para o Empreendedor Eta, os maiores obstáculos enfrentados estão relacionados a fatores internos, pois seus problemas estavam mais na forma de lidar com os problemas diários e na sua falta de capacitação pessoal do que em fatores externos à organização. 
As dificuldades elas sempre aparecem quando você tá na gestão de uma empresa, porque nenhuma é igual o mercado então as adaptações precisam existir. É claro que a sua bagagem profissional ou o seu conhecimento vão diminuir as dificuldades ou o impacto que as dificuldades possam ter sobre nossas vidas, e claro que vão sempre existir mais tem que tentar a resolução disso (Empreendedor Zeta).

Dessa forma, para esse empreendedor, a obtenção de conhecimento, fator de sobrevivência segundo o SEBRAE (2008), é algo utilizado para combater as dificuldades enfrentadas no dia a dia, minando o impacto e auxiliando a encontrar soluções para os desafios impostos.

A trajetória de vida dos empreendedores entrevistados traz histórias de sacrifício, trabalho árduo e prematuro, seja na feira ou em pequenos negócios familiares.

Trajetória foi de sacrifício, desde novo, comecei no ramo de bijuterias, confecções, armarinhos, tecido. Estabelecido, né? Mas quando comecei, foi vendendo, vender coisa na rua, sonho, vender limpa sapato, carregar feira. No começo foi assim. Agora quando eu estabeleci, foi vendendo bijuterias, vendendo miudeza de armarinho, confecções, tecido aí depois veio importados né (Empreendedor Alfa).

Sendo assim, este empreendedor iniciou sua trajetória empresarial desde criança, em trabalhos inicialmente informais, e, após esse período, pôde-se estabelecer em empreendimentos oficiais.

O Empreendedor Eta, que iniciou sua trajetória empreendedora ainda na escola, inseriu-se nos mais diversos ramos, desde o comércio de vestuário até o de eletrônicos e, atualmente, atua no ramo de alimentação.

Eu comecei com 16/17 anos vendendo roupa com minha mãe, sem loja nem nada, depois vendi dvd, eletrônicos é... depois comecei com calçados, depois o banco e depois aí e teve um monte de ideia que não deu certo, que se eu contar aqui não dá nem tempo e foi muita coisa e depois disso veio o [Empresa Eta], a hamburgueria, a pizzaria e nesse meio tempo aí do [Empresa Eta] eu comecei uma de consultoria também (Empreendedor Eta).

Sobre a possibilidade de encerrar as atividades empresariais, todos os empreendedores com empresas ainda em funcionamento afirmaram que, mesmo encarando dificuldades, não pensam em acabar com seus negócios. Embora enfrentem por vezes o desânimo, buscam paciência para se manter no ramo, tentando superar os problemas relacionados à questão financeira, à falta de clientes ou ao descomprometimento de funcionários: "Às vezes, desanima um pouco quando a gente vê um funcionário que não veste a camisa, que sai um cliente insatisfeito, mas assim pensar em fechar, nunca pensei" (Empreendedor Beta).

Quando a gente tentou no início e trabalhar e vender sem cliente e não ter preço de colocar, mas posteriormente foi a paciência e ver que o certo era esse. E a gente tentou parcerias de diversos tipos, com pedreiro, com engenheiro e a que deu mais certo foi com o próprio cliente, os influenciadores que a gente pensava que seria uma coisa mais certa, nem sempre foram tão acessíveis assim a dificuldade foi grande, mas trabalhando devagarzinho foi onde a gente viu essa eficácia que a gente podia ter. $\mathrm{O}$ restante foi trabalho interno mesmo de eeee controle e adaptação de maquinário para melhorar que tem muita necessidade de manutenção e diminui a produtividade, que para de produzir (Empreendedor Epsilon).

A paciência, a busca de clientes externos e a melhoria interna da empresa foram fatores que auxiliaram na manutenção da empresa e 
na prevenção do encerramento das atividades. Estes são fatores apontados pelo SEBRAE $(2008,2010)$ como internos, envolvendo o planejamento gerencial e o comportamento dos empreendedores em si, visto que afetam não só o desenvolvimento da empresa em si, mas também a forma como ela lida com as dificuldades enfrentadas no dia a dia. Valcácio et al. (2017) apontam que o comportamento proativo e as práticas gerenciais e de empreendedorismo são os fatores mais importantes, corroborando a fala dos empreendedores.

Sobre a continuação de empreendimentos, o Empreendedor Zeta afirma que a "adrenalina da profissão" é o que lhe mantém nos negócios, tanto quando estava ativamente trabalhando no seu próprio negócio, quando trabalhando para outrem.

Os relatos denunciam que a trajetória de vida dos empreendedores foi importante para elaborar suas visões do mundo e a forma como enxergam as dificuldades e os acertos, visto que cada experiência os levou ao momento e à situação atual. A fala do Empreendedor Eta confirma tal análise: "Não, eu sou o resultado delas." Ao ser perguntado sobre as empresas que teve que fechar, respondeu: "Não, porque se eu mudasse lá, acho que o futuro mudaria." Sua resposta, portanto, foi um indício de que não possuía arrependimentos quanto à sua trajetória. Porém, o Empreendedor Diagrama, que passou somente por um insucesso, afirmou que se pudesse voltar no tempo, não teria cometido os mesmos erros e teria começado "da forma que eu queria começar sem influência de outras pessoas". Ou seja, houve arrependimentos.

O Empreendedor Beta afirma que, se pudesse voltar no tempo, teria desacelerado e passado mais tempo com sua família e amigos. No entanto, hoje, sua postura é diferente: "[...] hoje eu coloquei na minha mente assim eu tenho que trabalhar o tempo que deu pra eu fazer, o que não deu, paciência, fazer no outro dia". Em outras palavras, o empreendedor experimenta arrependimentos ao ter colocado o trabalho acima da família. O Empreendedor Epsilon afirmou que o que mudaria em sua tra- jetória empresarial seria somente aquilo em que errou, seja nos negócios, seja em desgastes pessoais com funcionários ou família. Diminuiria, também, o impacto dos problemas pessoais no negócio. Segundo o SEBRAE (2008), um dos fatores que interferem na mortalidade das empresas tem acentuada relação com a interferência de problemas de caráter pessoal.

(pausa) acredito que... sempre há o que a gente teve com erro, desacerto, arrependimento e você acredita que é possível fazer algo pra melhorar. Então acredito que mudaria sim, algumas coisas, pra melhorar que forma feitas erradas de forma precipitada, no calor do momento, de forma de deixar de é tanto acontecer alguma cosia de necessidade de recuperação, um desgaste com alguém, cliente, funcionário, familiar e quando se fala de empresa também, algumas cosias foram feitas e refeitas então se pudesse voltar, já faria da forma definitiva, né (Empreendedor Epsilon).

Para o Empreendedor Zeta, a busca por conhecimento é um elemento que gostaria de mudar, se fosse possível voltar ao passado.

\begin{abstract}
Sim. Mudaria, eu investiria mais em conhecimento. Eu teria... eu teria... fazer igual a música estudado mais, eu teria cuidado um pouco mais dessa parte de conhecimento por que assim, sempre tive aquela coisa na vida que dificulta um pouco mais a questão do estudo e por conta da família, por conta até mesmo dos trabalhos então acaba dificultando assim, restringindo um pouco mais isso e a gente precisa dispor de um pouco mais de tempo. Então eu teria investido um pouco mais no estudo (Empreendedor Zeta).
\end{abstract}

O conhecimento é considerado um dos pontos mais importantes para os empreendedores e para a manutenção de seus empreen- 
dimentos, inclusive, é tido como um fator de sobrevivência para as empresas, segundo o SEBRAE (2008), Drucker (2011) e Nassif, Ghobril e Amaral (2011). A trajetória de vida dos empreendedores pesquisados é, portanto, de trabalho árduo, busca por capacitação e constante aprendizado, além de superação de problemas, a fim de manter suas empresas em funcionamento, buscando aumentar as chances de sobrevivência e minando os fatores de mortalidade. Suas trajetórias foram marcadas por dificuldades, estabilidade e crescimento nos negócios, buscando sempre a inovação, mesmo que corressem riscos moderados, e procurando, constantemente, conhecimento, conforme aponta Julien (2010), como características adquiridas pelos empreendedores. Corroborando o que fora proposto por Greatti e Sehorini (2000), Julien (2010) e Drucker (2011), os empreendedores entrevistados são também persistentes, aprendem com seus erros, são apaixonados pelo que fazem e apresentam capacidade para inovar.

Em suma, os principais motivos para a abertura de empreendimentos relatados pelos empreendedores foram a experiência prévia no ramo e a influência familiares e de outras pessoas, que os inspiraram a criar o próprio negócio. Os motivos para o encerramento são atrelados, em sua maioria, a falta de conhecimento e a fatores financeiros. Isso demonstra, ao mencionarem experiências prévias e falta de experiência, que a trajetória vivida e os conhecimentos obtidos ao longo de suas trajetórias foram importantes tanto para a abertura quanto para a manutenção e o encerramento dos empreendimentos.

Em síntese, os empreendedores que participaram da presente pesquisa foram construídos como tais em função das experiências vividas ao longo de suas trajetórias, percebendo seus erros e acertos, buscando manter-se em seus empreendimentos, aplicando também os conhecimentos em novos negócios, crescendo pessoal e profissionalmente por meio da persistência e buscando, constantemente, capacitar-se. A trajetória de cada um deles construiu suas percepções da vida e, consequentemente, moldou suas visões de sucesso e fracasso.

\section{CONSIDERAÇÕES FINAIS}

A presente pesquisa objetivou discutir os motivos para abertura e encerramento de atividades empresariais, assim como as dificuldades enfrentadas ao longo de suas trajetórias uma vez que a continuidade e/ou o encerramento de uma atividade empresarial traz impactos para a economia de uma região.

No que tange ao perfil dos empreendedores entrevistados, a maioria é de homens, na faixa etária entre 31 e 50 anos, casados, com, pelo menos, dois filhos, que estudaram até o ensino superior incompleto e não participaram de cursos; além da formação escolar, atuaram em seus negócios por, pelo menos, nove anos e já possuíram, ou possuem, mais de uma empresa em sua trajetória empresarial. Os empreendimentos são, em sua maioria, do ramo comercial e de serviços, sendo fundadas há, pelo menos, 10 anos.

Os motivos que levaram à abertura dos empreendimentos foram, em sua maioria, a necessidade e a influência familiar, assim como o reconhecimento de oportunidades de negócio, advindos do conhecimento prévio da área que pretendiam se inserir, além da inquietude e do desejo de criação. A falta de conhecimento sobre o ramo foi considerada pelos empreendedores entrevistados como um dos motivos pelos quais as atividades de seus empreendimentos foram encerradas, assim como fatores financeiros, como a dependência de cliente único e a necessidade de buscar outras formas de sustento em função das dificuldades econômicas e antecipação dessas dificuldades.

As principais dificuldades enfrentadas pelos empreendedores pesquisados foram os conflitos interpessoais, principalmente com funcionários, a falta de mão de obra especializada, a sobrecarga de atividades, em função da dificuldade de delegar, assim como problemas com fornecedores, a falta de cliente e o crescente número de concorrentes. Salienta-se que estes são também considerados como fatores 
que podem levar ao encerramento das atividades de um empreendimento. A trajetória de vida dos empreendedores pesquisados foi descrita, portanto, como de trabalho árduo e constante busca por capacitação e aprendizado, assim como superação de problemas e manutenção da empresa. Foram relatados, também, momentos de dificuldades, assim como momentos de estabilidade e crescimento, persistência e busca por aprendizado e inovação. Assim, entende-se que a trajetória de vida dos empreendedores é atrelada a seu percurso empresarial, pois cada momento de dificuldade ou de estabilidade os levou ao momento atual de suas vidas e às definições que propuseram ao longo da pesquisa.

Sugere-se, como pesquisas futuras, o aprofundamento em estudos acerca da trajetória de vida dos empreendedores e sua relação com a manutenção de seus empreendimentos. Outro ponto para pesquisa futura é a relação entre a resiliência e a trajetória da vida.

Entre as limitações encontradas na pesquisa, salientam-se a pequena amostra e a dificuldade de os entrevistados abordarem temas como o insucesso. Os depoimentos denunciaram a dificuldade de se falar do fracasso. Outra limitação está na pouca literatura sobre o tema, que traz, em maior escala, o debate em torno de sucesso do que insucesso, indicando que este tema ainda é um desafio nos Estudos Organizacionais.

\section{REFERÊNCIAS}

ALVES, Rita de Cássia Oliveira Lima et al. Perfil Empreendedor: um estudo exploratório sobre as características pessoais de Micro e Pequenos Empresários do Setor Moveleiro de Vitória da Conquista/BA In: ENCONTRO DE ESTUDOS SOBRE EMPREENDEDORISMO E GESTÃO DE PEQUENAS EMPRESAS, 6., 2010, Recife. Anais [...]. Recife: Editora Eletrônica Uni Soluções, 2010.

BARROS, Francisco Sávio de Oliveira; FIUSA, João Luiz Aexandre; IPIRANGA, Ana Silvia Rocha. O empreendedorismo como estratégia emergente de gestão: histórias de sucesso.
Organ. Soc., Salvador, v. 12, n. 33, p. 109-128, jun. 2005.

BORGES, Regiane Paulo; OLIVEIRA, Dora Maria de. sobrevivência e mortalidade das micro e pequenas empresas: estudo dos fatores determinantes e condicionantes. Enciclopédia Biosfera: Centro Científico Conhecer, Goiânia, v. 10, n. 19, p. 506-512, 6 nov. 2014.

CORREA, Victor Silva. Empreendedorismo e vinculação social: análise a partir de organizações religiosas. Revista de Empreendedorismo e Gestão de Pequenas Empresas, São Paulo, v. 6, n. 3, p. 616-645, dez. 2017.

COUTO, Marcelo Henrique Gomes; CAMPOS, Patricia Carvalho; CASTRO, Amanda Cristina. Mortalidade Precoce Das Micro e Pequenas Empresas: identificação e análise das principais causas de falência empresarial em Bambuí/MG. In: SEMINÁRIOS EM ADMINISTRAÇÃO, 19., 2016, São Paulo. Anais [...]. São Paulo: FEA/USP, 2016.

DEMO, Pedro. Pesquisa Participante: mito e realidade. Brasília: UnB/INEP, 1982.

DRUCKER, Peter Ferdinand. Inovação e Espírito Empreendedor (entrepreneurship): práticas e princípios. 11. ed. São Paulo: Cengage Learning, 2011.

DYNIEWICZ, Ana Maria. Metodologia da pesquisa em saúde para iniciantes. 2. ed. São Caetano do Sul, SP: Difusão Editora, 2009.

FARAH, Osvaldo Elias et al. O Empreendedor. In: FARAH, Osvaldo Elias; CAVALCANTI, Marly; MARCONDES, Luciana Passos. Empreendedorismo estratégico. São Paulo: Cengage Learning, 2008. cap.1, p.1-15.

FILARDI, Fernando. Estudo dos fatores contribuintes para a mortalidade precoce de micro e pequenas empresas da cidade de São Paulo. 2006. 163 p. Tese (Doutorado em 
Administração) - Programa de Pós-Graduação, Departamento de Administração da Faculdade de Economia, Administração e Contabilidade, Universidade de São Paulo, São Paulo, 2006.

FILION, Louis Jacques. O planejamento do seu sistema de aprendizagem empresarial: identifique uma visão e avalie o seu sistema de relações. Rev. adm. empres., São Paulo, v. 31, n. 3, p. 63-71, set. 1991.

FILION, Louis Jacques. Visão e relações: elementos para um metamodelo empreendedor. Rev. adm. empres., São Paulo, v. 33, n. 6, p. 50-61, nov./dez. 1993.

FILION, Louis Jacques. Empreendedorismo: empreendedores e proprietários-gerentes de pequenos negócios. Revista de Administração, São Paulo v. 34, n. 2, p. 6-28, 1999.

GEROLIM, Jhonni Kleyto dos Santos; ALBUQUERQUE, Alexandre Farias; VERGA, Everton. Comportamento Empreendedor do Dirigentes de Pequenas Empresas do Setor Varejista e de Serviços em Três Lagoas - MS. In: ENCONTRO DE ESTUDOS SOBRE EMPREENDEDORISMO E GESTÃO DE PEQUENAS EMPRESAS, 6., 2010, Recife. Anais [...]. Recife: Editora Eletrônica Uni Soluções, 2010.

GIL, Antônio Carlos. Como elaborar projetos de pesquisa. 4. ed. São Paulo: Atlas, 2002.

GIL, Antônio Carlos. Métodos e técnicas de pesquisa social. 6. ed. São Paulo: Atlas, 2008.

GOMES, Almiralva Ferraz. Ação empreendedora e relações de gênero: um estudo multicasos na cidade de Vitória da Conquista, Bahia. 2010. 440 f. Tese (Doutorado em Administração) - Universidade Federal de Lavras, Lavras, 2010 .

GOMES, Almiralva Ferraz; LIMA, Juvêncio Braga de; CAPPELLE, Mônica Carvalho Al- ves. Do Empreendedorismo à noção de Ações Empreendedoras: reflexões teóricas. Revista Alcance, Itajaí, v. 20, p. 203-220, 2013.

GREATTI, Ligia; SENHORINI, Vilma Meurer. Empreendedorismo: uma visão comportamentalista. In: ENCONTRO DE ESTUDOS SOBRE EMPREENDEDORISMO E GESTÃO DE PEQUENAS EMPRESAS, 1., 2000, Maringá. Anais [...]. Maringá: ANEGEPE, 2000.

GUIMARÃES JÚNIOR, Edward Humberto. Como os empreendedores trabalham: uma leitura psicodinâmica da organização do trabalho de um grupo de empreendedores. Revista de Empreendedorismo e Gestão de Pequenas Empresas, São Paulo, v. 8, n. 1, p. 149-175, jan. 2019.

HIRISH, Robert; PETERS, Michael. Empreendedorismo. 5. ed. Porto Alegre: Bookman, 2004.

JULIEN, Pierre-André. Empreendedorismo regional e a economia do conhecimento. São Paulo: Saraiva, 2010.

LENZI, Fernando César; SANTIAGO, Nelson Marcelo. A ação empreendedora. In: LENZI, F. C.; KIESEL, Marcio Daniel; ZUCCO, Fabricia Durieux. A ação empreendedora. São Paulo: Editora Gente, 2010.

MACHADO, Hilka Pelizza Vier et al. O processo de criação de empresas por mulheres. RAE-eletrônica, v. 2, n. 2, jul./dez. 2003. Disponível em: http://www.scielo.br/scielo. php?pid=S167656482003000200007\&scrip$\mathrm{t}=$ sci_abstract\&tlng=pt. Acesso em: 24 fev. 2019.

MINELLO, Italo Fernando. Resiliência e insucesso empresarial: um estudo exploratório sobre o comportamento resiliente e os estilos de enfrentamento do empreendedor em situações de insucesso empresarial, especificamente em casos de descontinuidade do negócio. 2010. 
Tese (Doutorado em Administração) - Faculdade de Economia, Administração e Contabilidade, Universidade de São Paulo, São Paulo, 2010.

MOCELIN, Daniel Gustavo; AZAMBUJA, Lucas Rodrigues. Empreendedorismo intensivo em conhecimento: elementos para uma agenda de pesquisas sobre a ação empreendedora no Brasil. Sociologias, Porto Alegre, v. 19, n. 46, p. 30-75, dez. 2017. Disponível em: http://www. scielo.br/scielo.php?script=sci_arttext\&pi$\mathrm{d}=\mathrm{S} 1517=45222017000300030-\& \overline{1} \mathrm{ng}=$ pt\&nrmiso. Acesso em: 24 fev. 2019.

NASSIF, Vânia Maria Jorge; GHOBRIL, Alexandre Nabil; AMARAL, Derly Jardim do. Empreendedorismo por Necessidade: O Desemprego como Impulsionador da Criação de Novos Negócios no Brasil. Pensamento \& Realidade, v. 24, n. 1, out. 2011. Disponível em: https:// revistas.pucsp.br/index.php/pensamentorealidade/article/view/7075. Acesso em: 24 fev. 2019.

PAULINO, Alice Dias; ROSSI, Sonia Maria Morro. Um estudo de caso sobre perfil empreendedor: características e traços de personalidade empreendedora. In: EGEPE - ENCONTRO DE ESTUDOS SOBRE EMPREENDEDORISMO E GESTÃO DE PEQUENAS EMPRESAS, 3., 2003, Brasília. Anais [...]. Brasília: UEM/UEL/ UnB, 2003. p. 205-220.

ROGERS, Everett. Diffusion of Innovation. New York: Free, 1995.

SANTOS, Eli Izidro dos; BARRETO, Ricardo da Candéa Sá; GUZMAN, Socrates Jacobo Moquete. Modelo Estrutural para os Fatores Determinantes da Oferta de Empreendedores Criativos: Ilhéus e Itabuna. Revista de Empreendedorismo e Gestão de Pequenas Empresas, São Paulo, v. 6, n. 1, p. 160-195, abr. 2017.

SCHUMPETER, Joseph Alois. A Teoria do Desenvolvimento Econômico. 2. ed. São Paulo: Nova Cultural, 1985.
SEBRAE (SP). 10 Anos de Monitoramento da Sobrevivência e Mortalidade de Empresas. São Paulo: SEBRAE-SP, 2008.

SEBRAE (SP). Doze anos de monitoramento da sobrevivência e mortalidade de empresas. São Paulo: SEBRAE-SP, 2010.

SEBRAE (SP). Causa Mortis: o sucesso e o fracasso das empresas nos primeiros 5 anos de vida. São Paulo: SEBRAE-SP, 2014.

SEBRAE (DF). Sobrevivência das empresas no Brasil. Brasília: SEBRAE, 2016.

SHANE, Scott; VENKATARAMAN, Sankaran. The promise of entrepreneurship as a field of research. Academy of Management Review, New York, v. 25. n. 1. p. 217-226, jan. 2000.

SMITH, Adam. Riqueza das nações. Rio de Janeiro: Editora Ediouro, 1986.

VALCÁCIO, Suzanne dos Anjos et al. A estratégia do SEBRAE e os fatores de sucesso e mortalidade precoce das micro e pequenas empresas conforme a literatura e visão dos gestores e consultores. In: SEMINÁRIOS EM ADMINISTRAÇÃO, 20., 2017, São Paulo. Anais [...]. São Paulo: FEA/USP, 2017.

VERGA, Everton; SILVA, Luiz Fernando Soares da. Empreendedorismo: evolução histórica, definições e abordagens. Revista de Empreendedorismo e Gestão de Pequenas Empresas, São Paulo, v. 3, n. 3, p. 3-30, 2014.

VINUTO, Juliana. A amostragem em bolsa de neve na pesquisa qualitativa: um debate em aberto. Temáticas, Campinas, v. 22, n. 44, p. 203-220, 2014.

YIN, Robert. Estudo de caso: planejamento e métodos. 2. ed. Porto Alegre: Bookman, 2001. 